\title{
A EDUCAÇÃO LIBERTADORA EM UMA UNIDADE SOCIOEDUCATIVA DE MATO GROSSO
}

\author{
LIBERATING EDUCATION IN A SOCIOEDUCATIONAL UNIT IN MATO GROSSO
}

Recebido: 15/04/2021

\author{
Dagoberto Rosa de Jesus ${ }^{1}$ \\ Tayza Codina de Souza Medeiros Guedes ${ }^{2}$
}

Aceito: 05/05/2021

Resumo: O artigo tem por objeto de estudo a preocupação da educação no sistema socioeducativo que assiste a adolescentes privados de liberdade e a projeção de uma educação libertadora nesse espaço. A construção do Plano Estratégico de Educação (PEE) nas unidades prisionais do estado de Mato Grosso proporcionou a reflexão da escolarização formal e a educação profissional. Nesse ínterim, o objetivo da pesquisa é avaliar como as atividades culturais, a abordagem social e psicológica, as práticas esportivas, a assistência religiosa e todas as demais atividades dirigidas aos adolescentes devem ter propósito de desenvolver seu potencial para ser e conviver. Diante disso, a escola "Meninos do Futuro" propõe-se fazer parte desta luta, e instrumentalizando seus alunos para que consigam reconhecer seus direitos e a necessidade de reivindicá-los. Dessa maneira, possibilita ludicidade no espaço escolar e dentro do centro socioeducativo, projetando uma educação libertadora. Como instrumento metodológico, o artigo apoiou-se nos teóricos: VYGOTSKY (1999), FREIRE (1995) e SOARES (2000).

Palavras-chave: Educação libertadora; Sistema socioeducativo; ludicidade.

Abstract: The article has as its object of study the concern of education in the socioeducational system that assists adolescents deprived of freedom and the projection of a liberating education in this environment. The construction of the Strategic Education Plan (PEE) in the prison units of the state of Mato Grosso has provided the reflection on formal schooling and professional education. In this regard, the objective of this research is to evaluate how the cultural activities, the social and psychological approach, the sports practices, the religious assistance and all the other activities directed to the adolescents should have the purpose of developing their potential to be and to live together. In view of this, the "Meninos do Futuro" school proposes to be part of this struggle, and to provide its students with the tools to recognize their rights and the necessity to claim them. In this way, it enables playfulness in the school environment and inside the socio-educational center, projecting a liberating education. As a methodological tool, the article was based on the theorists: VYGOTSKY (1999), FREIRE (1995) and SOARES (2000).

Keywords: Liberating education; Socio-educational system; playfulness.

\footnotetext{
${ }^{1}$ Doutorando pela Instituição (UNEMAT/PPGEL). Professor na Instituição (IFMT/PDL), Primavera do Leste, Mato Grosso, Brasil. E-mail: dagoberto.jesus@pdl.ifmt.edu.br

${ }^{2}$ Doutoranda pela Instituição (UNEMAT/PPGEL). Professora na Instituição (IFMT/PDL), Primavera do Leste, Mato Grosso, Brasil. E-mail: tayza.souza@pdl.ifmt.edu.br
} 


\section{Introdução}

Pensar educação no Brasil foi e é um grande desafio posto para nós gestores de educação, educadores, pais e sociedade em geral. Esse desafio é maior na medida em que nos vemos num regime competitivo e excludente regido pelo signo do capital e da exclusão.

Compartilhando do sonho de uma sociedade mais igualitária, muitos brasileiros viram e vêem na educação um caminho para a construção de um Brasil e de um mundo melhor. Nessa senda, encontramos nomes como Paulo Freire, Anísio Teixeira, Darcy Ribeiro, entre outros, que além de suas lutas pessoais deixaram um legado de ideias que ainda hoje iluminam nossos caminhos e pensar, estarão presentes aqui também nessa escrita.

Frente a este panorama em que a práxis educativa tem por buscar uma educação mais humanizadora e menos excludente como um norte, falar sobre educação no sistema socioeducativo, ou educação para pessoas que estão privados de liberdade esse espaço nos parece relevante e oportuno.

$\mathrm{Na}$ margem social o indivíduo privado de liberdade pede um olhar dos gestores de educação mais atento, a exemplo do que hoje já fazemos com a educação no campo, a educação de quilombolas, de indígenas e na educação de jovens e adultos.

Em nosso objeto de estudo o que buscamos deriva da preocupação da educação no sistema socioeducativo que assiste a adolescentes privados de liberdade. Refletir e pensar ações propositivas na educação de jovens privados de liberdade é o objetivo deste trabalho que tem uma meta que ultrapassa a obrigatoriedade do texto para melhoramento do currículo e adentrar no cotidiano da escola que trabalha dentro do sistema socioeducativo, em particular na Escola Estadual Meninos do Futuro.

No estado de Mato Grosso, a discussão do ensino sistema prisional começou a se esboçar de forma sistemática e efetiva em 2010, no Seminário para a construção do Plano Estratégico de Educação (PEE) nas unidades prisionais do estado de Mato Grosso. Como o nome sugere esse evento teve como foco principal o sistema prisional para adultos. Quanto ao sistema socioeducativo, representado no Estado de Mato Grosso, pelo chamado centro socioeducativo que tem sua educação formal sobre a responsabilidade da escola estadual Meninos do Futuro ligada à Secretaria de Estado de Educação - (SEDUC), ainda não se tem um PEE para as unidades socioeducativas.

Do lugar de educador e atento a sua especificidade desta instituição busca-se pensar em que medida as ações da gestão corroboram para uma práxis humanizadora. Sem perder de vista que a escola, no contexto de adolescentes privados de liberdade, se coloca como lócus 
que garante o direito destes à educação.

O Estatuto da Criança e do Adolescente (ECA), instituído pela Lei 8.069, de 13 de junho de 1990, contrapõe-se historicamente a um passado de controle e exclusão social sustentado na doutrina da proteção integral. Pela primeira vez na história brasileira, a questão social do adolescente tem prioridade absoluta, transformando o mesmo em cidadãos sujeito de direitos e deveres, estabelecendo regras de prioridades dentro das políticas públicas, trazendo através dos seus artigos, princípios inovadores como a ampliação e divisão das responsabilidades entre a família, o Estado, a sociedade e a comunidade, conforme preconiza o artigo $4^{\circ}$ do Estatuto da Criança e do Adolescente - ECA Lei 8.069/90.

O Estatuto da Criança e do Adolescente é no Brasil, a produção dos avanços internacionais no campo da promoção e defesa dos direitos humanos da população infantojuvenil. Apesar de todo o compromisso político e de grande conquista na promoção dos direitos humanos no Brasil, ainda se tem como desafio a materialização desses direitos.

Grande número de adolescentes vive privados de condições de acesso a patamares mínimos de desenvolvimento, bem-estar, cidadania e políticas públicas que possam fomentar seus direitos. Tais situações os tornam um segmento de elevada vulnerabilidade social. Nesta proliferação de estados de desigualdade, de miséria e de injustiça, eles são propulsores de várias violências: familiar, social, ética, psicológica e estrutural, prejudicando enormemente a qualidade das inter-relações humanas.

Os atos infracionais constituem um fenômeno extremamente complexo, derivando da inter-relação dinâmica de muitas variáveis presentes na vida cotidiana, em que sujeitos são agentes e pacientes ao mesmo tempo.

A aplicação da medida socioeducativa é acima de tudo, uma resposta formal da sociedade e um delito pelo qual o adolescente, após submeter-se ao devido processo, com todas as garantias, foi considerado responsável.

Todos os adolescentes deverão ser beneficiados com medidas para ajudar na sua formação e reintegração na sociedade, contando com a garantia da política de atenção integral, através do sistema de proteção e defesa dos direitos da criança e do adolescente.

A natureza essencial da ação socioeducativa é a preparação do jovem para o convívio social. A escolarização formal, a educação profissional, as atividades culturais, abordagem social e psicológica, práticas esportivas, assistência religiosa e todas as demais atividades dirigidas ao adolescente devem ter propósito de desenvolver seu potencial para ser e conviver.

Apesar dos avanços obtidos até aqui, há que substituir as práticas assistencialistas e correcionais-repressivas por um modelo garantista, capaz de trazer as conquistas do estado 
democrático de direitos para o interior dos sistemas de administração da justiça juvenil.

Para realizar esses pensares organizaremos este trabalho em três momentos que pensamos se complementam, a saber; um rito de passagem, a educação no sistema socioeducativo e suas especificidades, a práxis pedagógica e a busca por uma abordagem lúdica. No primeiro contextualizamos a escola estadual Meninos do Futuro e suas especificidades no sistema socioeducativo, na sequência apresentamos as diretrizes do atendimento no sistema socioeducativo.

Em um terceiro momento apresentamos a luz das leituras e releituras que apontam para uma prática libertária e lúdica.

\section{$2 \mathrm{Um}$ rito de passagem}

O mito de Ícaro fala-nos da imprudência do jovem, na sua dificuldade de ouvir o pai, o mais velho, o responsável que lhe apresenta as regras do viver. Ao se verem donos de seus voos e de seus caminhos, muitos jovens buscam voar mais alto do que é permitido e muitas vezes em um voar cego que busca aventuras, prazeres e caminhos que podem custar a sua própria liberdade, e a sua própria vida.

Muitos dos jovens que atendemos, alunos da Escola Meninos do Futuro, têm nesse mito sua história. Buscamos fazer com que esses "Ícaros" ouçam a voz da experiência, para que sejam prudentes e assim não se precipitem em seus vôos. Para que não tenham na imprudência e na desobediência às suas principais conselheiras e consigam fugir do destino do mito grego para serem homens fortes, saudáveis, felizes, enfim, bons cidadãos.

$\mathrm{Na}$ busca por esse trabalho com jovens está o sentido da escola Meninos do Futuro, que se emana a outras instituições que tem no Estatuto da Criança e do Adolescente - uma referência por um atendimento digno aos adolescentes privados de liberdade, ou seja, seu Norte. A escola constitui-se num espaço de acolhimento, organização e socialização dos saberes, um espaço de atuação político - pedagógico, questionadoras das políticas sociais.

A Escola "Meninos do Futuro" propõe-se fazer parte desta luta, instrumentalizando seus alunos para que consigam reconhecer seus direitos, assim como a necessidade de reivindicá-los. Além disso, dentro de seu próprio espaço, a escola se propõe em assegurar um projeto político administrativo pedagógico e cultural que com propósitos de resgatar a cidadania e os direitos de seus educandos e, possibilitando a construção de projetos de vida rumo a sua inserção social.

Nesse labor hercúleo, a escola estadual Meninos do Futuro trabalha para buscar uma educação formal para esses adolescentes que estão sob a tutela do estado, privados de 
liberdade à margem social. Acredita-se, a exemplo de Paulo Freire, que a educação é uma ação libertária e é aqui nesse contexto onde tudo que não se tem é liberdade, que a sua necessidade nos parece mais clara e mais urgente.

\section{A educação e a privação da liberdade}

Pensar, observar e refletir a sociedade, nos possibilitam olhar as nossas mazelas, refletir sobre elas e lutar na busca de corrigir o que é necessário corrigir, para assim termos uma sociedade mais igualitária.

A escola Meninos do Futuro busca resgatar um tempo perdido, posto que esses adolescentes ao estarem no sistema socioeducativo, em que perdem sua "liberdade", tem o tempo de rememorar e de reelaborar suas experiências e assim quem sabe mudar a trajetória de suas vidas. Diferente do texto "Em busca do Tempo Perdido" de Marcel Prost esses adolescentes não buscam um tempo de alegria no passado. A eles o passado é quase sempre muito igual, um acúmulo de tristezas e de abandonos, salvo, raras exceções, repetem uma história que nos parece sem fim, e que nos é contada há muito tempo.

Ao estudar o adolescente, suas crises, suas contradições, e a violência em que, às vezes, ele se envolve, é preciso vê-lo no contexto de que está inserido. A violência, para alguns, tem sido uma forma de manifestar sua indignação e protesto pela miserabilidade que o sistema impõe para grande parte desses sujeitos que não possuem suas necessidades básicas de sobrevivência supridas notadamente em alimentação, saúde, escola e lazer. Mas, por igual, é necessário considerar a violência em seus aspectos inconscientes e históricos.

A escola estadual Meninos do Futuro, responsável pelo atendimento escolar de adolescentes em conflito com a lei e, internos no centro socioeducativo em Cuiabá, tem características peculiares, por se tratar de uma escola que foi criada especificamente para atender crianças e adolescentes vitimizados pela própria sociedade, necessidades especiais e privados de liberdade, cumprindo medida socioeducativa conforme determinação judicial.

Enquanto educador, convivendo com os alunos detectamos por meio de pesquisa, estudos descritivos, participação em diversos projetos pedagógicos, evidencia as dificuldades que os alunos apresentam para: interpretar um problema de matemática, um texto de ciências, um livro de literatura, expressar suas ideias, o que sentem e o que pensam através da escrita.

O estudo da língua portuguesa e a leitura são ingredientes básicos e fundamentais nesse processo. Quem lê e interpreta o que leu, resolve qualquer problema e escreve bem. A linguaguem e o pensamento nascem da vida, por isso é necessário que o aluno viva intensamente a realidade. 
Sendo assim, na escola estadual Meninos do Futuro é necessário que sejam oferecidas ao aluno diferentes oportunidades de desenvolver as habilidades linguísticas básicas - falar ouvir, ler e escrever num texto de reflexão e de análise que não deixe de enfatizar o universo das emoções, conhecimento e satisfação pessoal. Tais atividades, podem oferecer como leitura em diferentes tipos de textos (jornais, revistas publicitárias, contos, crônicas, poemas, poesias, letra de músicas, romances, etc.), atividades reflexivas que possam fazer deste contexto uma oportunidade de compreensão e sistematização dos mecanismos de funcionamento da língua.

As ações pedagógicas desenvolvidas estão voltadas ao protagonismo juvenil e à participação crítica-construtiva do aluno, promovendo a construção de uma sociedade em que todos possam estabelecer diálogos em igualdade de condições e capacidade para tomada de decisões que levem mudanças futuras da sociedade. Para isso é necessário a formação de leitores críticos e, caberá aos alunos socializar esses saberes em benefício da maior autonomia intelectual das novas gerações, assim como efetiva a participação na implementação das políticas sociais para o desenvolvimento de ações integradas que levem em consideração as peculiaridades que cercam o atendimento ao adolescente em conflito com a lei.

Por entender assim, a escola propõe um trabalho intensivo para, com o objetivo de despertar o gosto de ler e, consequentemente, formar alunos capazes de interpretar bem o que lêem e de se expressar corretamente, esperando que, aos poucos, cada um se torne um verdadeiro leitor.

Diante das características e do perfil de nossos alunos, faz-se necessário que os professores desenvolvam no âmbito da escola uma pedagogia da presença, no sentido de resgatar o que há de positivo na conduta desses adolescentes. O estar junto desse aluno é um ato que envolve uma relação pessoal positiva. $O$ aluno precisa que suas necessidades de estima sejam satisfeitas, isto é, precisa sentir-se compreendido e aceito.

As ações educativas devem exercer uma influência edificante na vida do adolescente. Se ele tiver a sensação de que tem valor para alguém e de que é compreendido e aceito, vai olhar o futuro sem medo, e será capaz de construir um projeto de vida.

Trabalhar com literatura na escola é promover a aprendizagem que sirva para a constituição de sujeitos que simplesmente não só pertençam a uma sociedade, porém a questiona e a transforma. Reitera-se, finalmente, a importância de despertar o gosto pela leitura. A leitura que nos transmite conhecimentos e nos faz viajar pela cultura mundial.

Portanto, para que o projeto Letramento viesse a fortalecer incentivamos a terceira ação que é a formação continuada com o projeto Sala do Professor que é de extrema importância visando o aperfeiçoamento das práticas educacionais, criando mecanismos para 
transformação social de todos envolvidos no processo; nas atitudes, mentalidades e valores sociais. Ser educador na escola Meninos do Futuro exige dos profissionais muito mais que preparação técnica. É necessário esforço coletivo na direção de um conceito e de uma prática mais humanizada, atendendo as especificidades das crianças e adolescentes vítimas de exclusão e violência de toda ordem.

Assim, o professor deverá apresentar dinâmicas interdisciplinares e atividades que vêm ao encontro das necessidades apresentadas pelos alunos. $\mathrm{O}$ educador tem o papel decisivo nessa mudança, e ele não pode estar alienado do seu fazer pedagógico.

A formação continuada é uma atitude de busca, superando o modelo que exclui, humilha, manipula, submete e, por outro lado, buscamos a avaliação processual, formativa e reguladora que inclui, contribui para a formação autônoma, para o verdadeiro exercício da cidadania.

Neste contexto do conhecimento, cabe aos profissionais, amar o conhecimento como espaço de realização humana, de alegria e de contentamento cultural, selecionar e rever criticamente a informação, ser provocadores de mensagens e não puros receptores, produzir, construir e reconstruir conhecimento elaborado. Os educadores não só transformam a informação em conhecimento e em consciência crítica, mas também formam pessoas.

As mudanças que o mundo contemporâneo vem sofrendo em diversos setores produtivos da sociedade, inclusive na educação, são provocados pelos avanços tecnológicos. Os educadores como profissionais responsáveis pela mediação da informação e da produção do conhecimento, desempenham papéis importantes na transformação dos indivíduos.

A formação continuada dos educadores torna-se assim, imperativo, não apenas para eles próprios, pelo preponderante papel que exercem em sala de aula.

O Projeto Letramento e de Implementação das Atividades Pedagógicas contribuiu com as principais dificuldades dos alunos, realizando as intervenções adequadas tendo como base a influência proativa, construtiva, criativa e solidária favorável ao desenvolvimento pessoal e social.

Por meio da lei 8.069/90, Estatuto da Criança e do Adolescente em seu artigo $4^{\circ}$ :

é dever da família, da comunidade, da sociedade em geral e do poder público assegurar com absoluta prioridade, a efetivação dos direitos referentes à vida, a saúde, a alimentação, à educação, ao esporte, ao lazer, à profissionalização, à cultura, à dignidade, ao respeito, à liberdade e à convivência familiar e comunitária.

A família tem um papel essencial junto ao desenvolvimento da socialização da criança, e ela quem medirá sua relação com o mundo e poderá auxiliá-la a respeitar regras limites e 
proibições necessárias à vida em sociedade.

No estudo de Galo Williams (2004 a 2004 b), a escola foi identificada como um fator de proteção para a não instalação de componentes antissociais.

Crescer em um ambiente livre de violência intrafamiliar, com uma educação apoiada em supervisão, diálogo, afeto e limites é um grande antídoto a criminalidade. Entretanto, quando às condições socioculturais associam-se às condições pessoais, os resultados negativos poderão ser intensificados. Viver em condições de pobreza, pertencendo a uma família desestruturada com um pai ausente e uma mãe sem autoridade, em uma comunidade sem lazer, com escolas precárias e sem perspectivas de trabalho, em que poderá levar um adolescente a comportamentos antissociais.

Adolescentes em cumprimento de medida socioeducativa apresentam características marcantes, resultantes das condições adversas vivenciadas: a falta de perspectivas na vida, elevadas doses de desesperança, falta de emprego, salários, exclusão escolar e outros que são incrementos da violência como reação a um estado frustrante e contraditório insuportável.

Nesta proliferação de estados cruéis de desigualdade, miséria e de injustiça, no meio psicossocial está agravado pelas discrepâncias socioeconômicas e culturais, elementos facilitadores de um clima de instabilidade social e propulsora de várias violências: estrutural, familiar, social, ética, psicológica prejudicando enormemente a relação das inter-relações humanas.

Os atos infracionais tendem a ser apenas um dentre várias outras formas de expressão dessas dificuldades e, por isso, não podem ser abordadas de forma isolada ou fragmentada. Diante disto, torna-se óbvio que a compreensão e o atendimento dos adolescentes passam necessariamente pela atenção ao contexto social.

Muito embora o Estatuto da Criança e do Adolescente apresente significativas mudanças e conquistas em relação ao conteúdo, ao método e a gestão, essas modificações ainda estão no plano jurídico e político-conceitual, não chegando efetivamente aos seus destinatários.

A educação e a inclusão social desses adolescentes transcendem a construção de altos muros de contenção. Antes, precisa aprender fundamentalmente a viver em liberdade, a adquirir o domínio de si mesmo; é preciso ensinar-lhes valores éticos e morais, despertá-los para o gosto pela leitura e para a importância da educação. Pouco ou quase nada é feito em termos de prevenção primária, na tentativa de evitar que mais adolescentes se envolvam em crimes. Neste contexto, faz-se extremamente importante o investimento nas políticas que atuam com crianças e adolescentes. É investir em projetos preventivos que não tratem apenas 
do emergencial, mas da formação do adolescente.

Os jovens não podem ser considerados apenas como parte do problema, mas devem ser vistos também como parte fundamental da solução. Os adolescentes devem ser protagonistas dos processos de mudanças. A participação da família, da comunidade e das organizações da sociedade civil voltada a defesa dos direitos do adolescente na ação socioeducativa é fundamental para a consecução dos objetivos da medida aplicada ao adolescente. As práticas sociais devem oferecer condições reais, por meio de ações e atividades programáticas à participação ativa e qualitativa da família no processo socioeducativo, possibilitando o fortalecimento dos vínculos e a inclusão dos adolescentes no ambiente familiar e comunitário.

A Escola tem buscado sensibilizar os alunos para o exercício da leitura e através dela, refletir sobre a criação de sujeito consciente e preparado para a construção da cidadania plena, em que o direito deve ser respeitado e deveres cumpridos.

A equipe gestora da escola estadual Meninos do Futuro oferece aos adolescentes que cumprem medida socioeducativa de internação, um atendimento que venha exercer influência em sua vida e que possa contribuir para a construção de sua identidade, possibilitando que assuma um papel inclusivo na dinâmica social e comunitária. Para tanto, é vital a criação de acontecimentos que fomentem o desenvolvimento da autonomia, solidariedade e de competências pessoais, cognitivas e produtivas.

Os profissionais deverão propiciar aos adolescentes na gestão pedagógica o acesso a direitos e oportunidades de superação de sua situação de exclusão, ressignificando valores, buscando soluções eficientes, eficazes e efetivas e, assegurando aos educandos que cometeram ato infracional a oportunidade de desenvolvimento e mudanças.

Os profissionais da escola, ao analisar o seu público alvo atenta-se as que enfrentam o que esperam da escola, suas crenças, seus valores morais e culturais. A escola tem como princípio o compromisso inalienável com a inclusão educacional de todos, estimulando a permanência e o sucesso na escola.

Ao entender a dinâmica da escola Meninos do Futuro ficam claras as suas especificidades, e contamos com o corpo docente que deve dedicar de forma exclusiva à escola, e tenha dentro da dinâmica da mesma uma postura propositiva.

O Projeto Letramento e de Implementação das Atividades Pedagógicas não surge como solução final para resolver os problemas dos adolescentes em relação à escola e escolaridade, mas certamente apresenta um conjunto de ações que visam minimizar de forma sistêmica um dos principais problemas de nossos alunos, a exclusão do mundo letrado. 
Letramento é um aspecto que deverá ser evidenciado por todos os professores, vista que, para SOARES (2000), a ação de letrar é mais que alfabetizar, é ensinar a ler e escrever de um contexto em que a escrita e leitura tenham sentido e façam parte da vida do aluno. Já não basta aprender a ler e escrever, é necessário mais que isso para ir além da alfabetização funcional. A autora sugere que alfabetizemos letrando sem descuidar da especificidade do processo de alfabetização.

A aprendizagem desperta processos internos de desenvolvimento que só podem ocorrer quando o indivíduo interage com outras pessoas. Aqui a importância da intervenção pedagógica que provoca avanços que não ocorreriam espontaneamente. O Processo de ensinoaprendizagem propicia o acesso dos membros imaturos da cultura letrada do conhecimento construído e acumulado pela ciência (VYGOTSKY, 1999).

Como descreve Jean Piaget (1896) o homem é um ser essencialmente social, impossível, portanto, de ser pensado fora do contexto da sociedade em que nasce e vive e que a socialização acontece através da troca intelectual entre indivíduos, sendo que o seu maior e melhor grau se dá quando a troca atinge o equilíbrio. Este ser social é justamente aquele que se relaciona de forma equilibrada com seus semelhantes.

Pensando uma alfabetização Global, os professores de alfabetização interviram no trabalho pedagógico envolvendo todas as facetas cognitivas, afetivas, social, econômica e cultural que o estudante apresenta. $\mathrm{O}$ trabalho interdisciplinar foi essencial para o estímulo do ensino aprendizagem vivenciados no processo de letramento e alfabetização. $\mathrm{O}$ aluno tornouse protagonista da sua própria construção, envolvendo os conhecimentos científicos e a realidade da vivência do aluno no contexto em que está inserido. $\mathrm{O}$ educando passou a ter responsabilidade e autonomia em suas ações diante de um processo de aprendizagem.

Em seus projetos os professores buscaram oportunizar a formação básica para a cidadania dando condições de desenvolver a aprendizagem como os meios básicos, o pleno domínio da leitura, da escrita e do cálculo, compreendendo o ambiente natural e social, em que se fundamenta a sociedade.

Pensamos em ações que valorizassem o lúdico nas diversas áreas do conhecimento destacamos: em linguagens, por exemplo, os professores em seus projetos consideraram que os alunos lêem pouco e não são motivados para essa prática. Com as atividades eles visam despertar a curiosidade e o interesse dos estudantes como fonte de informação e prazer

Alguns professores da linguagem trabalharam com alunos que apresentavam dificuldades na produção de textos e que não conseguiram entender o que lêem, e que tiveram afastados das atividades escolares por muito tempo. Buscaram desenvolver as habilidades de 
interação oral e escrita a partir do grau de letramento que o aluno traz de seu grupo familiar e cultural, a partir da promoção de: estratégias como oficinas de produção de textos narrativos, poéticos, teatrais e informativos; Gincanas recreativas com poesias /cantos; Concursos literários - poesias e contos; Elaboração de um livro de poesias dos próprios alunos; Teatro, informativo jornalístico da autoria dos alunos; Seminários com apresentação e exposições dos trabalhos produzidos por eles; A escrita de cartas como meditação da leitura literária; Leitura e produção de cartas literárias e não literárias; Desenvolvimento de literatura e vida cultural, com perspectiva de trabalhar as transformações sociais contemporâneas; Construção de uma postura crítica e reflexiva diante do jornalismo e do jornal brasileiro; Leitura e interdisciplinaridade.

Em educação artística o projeto trabalha com atividades plásticas oportunizando o aluno a se expressar por meio do conhecimento da arte e de sua produção nos trabalhos artísticos, criando trabalhos de suas autorias, imprimindo suas marcas subjetivas e expressando ideias e percepções recriando, fazendo uma nova leitura, uma releitura de obras do artista Van Gogh.

$\mathrm{Na}$ área de ciências da natureza e também em ciências humanas e sociais com base nas dificuldades de assimilação de conteúdos e, por consequência, dificuldades de aprendizagem, os professores de cada componente destas áreas apresentaram seus respectivos projetos de intervenção. Na disciplina de matemática o uso do jogo de xadrez é um dos jogos mais antigos e populares do mundo, o xadrez pode ser aproveitado em vários aspectos pedagógicos. A partir dele é possível estimular o desenvolvimento de habilidades cognitivas, como: atenção, disciplina, memória, concentração, raciocínio lógico, inteligência e imaginação. O xadrez proporciona aos alunos a oportunidade de conhecer e aprender o jogo e utilizá-lo para desenvolver suas habilidades cognitivas, democratizando esse jogo arte-ciência popularizando-o na escola.

Assim, cria condições para o desenvolvimento, interação e o sentido de grupo, além do aprendizado do esporte, eventos motivadores a prática do jogo e à interação ao projeto realizando vivências e palestras.

Em biologia, por exemplo, o projeto horta escolar tem como premissa básica reforçar e enriquecer a merenda escolar e resgatar o plantio de horta doméstica colocando o aluno em contato com a terra, permitindo a interatividade da ação educacional na relação direta com o fazer cultural e as relações do homem com a terra. Utilizando leitura de texto sobre horta escolar; discussão e debates sobre a importância de uma alimentação variável; preparo do terreno para o plantio; selecionar as hortaliças que serão plantadas; utilização das hortaliças 
no consumo da merenda escolar.

Em história, tendo em vista a dificuldade de assimilação de conteúdo e por consequência aprendizagem dos alunos, a exibição de filmes que juntamente com os conteúdos da disciplina de história melhoraram sensivelmente o aprendizado dos alunos nos níveis fundamental e médio. Promover exibição de filmes - estimula nos alunos hábitos de leitura, interpretação de texto, compreender e analisar especificidades contidas nos filmes, confrontando e refletindo sobre diferentes fontes históricas e espaciais analisando fatos nas perspectivas históricas e geográficas.

A disciplina de geografia viabilizou o conhecimento dos diferentes tipos de paisagens do estado de Mato Grosso, levando os alunos a observarem e perceberem quanto à ação do homem pode ser positiva ou negativa na natureza, buscando formar cidadão consciente de suas responsabilidades individuais e coletivas, por meio de um trabalho de humanização, trabalhando a auto-estima, o auto-conceito, para que se sinta sempre motivado ao próprio aperfeiçoamento enquanto pessoa, enquanto cidadão.

Os professores promoveram pesquisas, leituras de textos, palestras com profissionais qualificados, debates e filmes; aulas expositivas com dinâmicas; realização de uma feira ecológica onde será apresentado teatro, dança, poesias sobre poluição, desmatamento, queimadas e erosão; confecção de mural ecológico; trabalho com sucatas feitas pelos alunos. Assim como mapas: paisagens urbanas e rurais; tipos de moradias, problemas ambientais, densidades demográficas, saúde, violência; maquetes - construção da autonomia dos estudantes.

A avaliação do Projeto acontece em cunho diagnóstico, reflexivo e formativo, privilegia a participação dos professores, coordenadores e alunos no acompanhamento do processo ensino aprendizagem. Prevêem registros sistemáticos das atividades e resultados alcançados por meio de cadernos, relatórios, portfólios, auto-avaliação do aluno, cartazes, painéis, bem como nos processos de observação periódica.

A partir dos resultados, o professor rever os procedimentos utilizados, processa a necessidade ou não de uma flexibilidade no âmbito da reelaboração do projeto e aplicação do mesmo, e os caminhos que mais contribuem para o sucesso do aprendizado dos alunos, a importância da autoestima, autoimagem e que ele é o principal sujeito desse processo.

\section{Considerações Finais}

Pensar educação para adolescentes em conflito com a lei e privados de liberdade é pensar em plantar esse ato de amor (que é educar) no coração de uma instituição onde não só 
falta liberdade como sobra sofrimento, ódio e dor.

Ao final desse trabalho que envolveu estudo, e um olhar sobre a unidade escolar podemos ver de forma mais clara o local de trabalho. Essa nova forma de ver, de observar a escola só foi possível pelas leituras. Chegando e checando nossas reflexões podemos observar que a gestão de uma unidade escolar pode mesmo mudar de forma significativa o rendimento de seus alunos e isso nos parece que reside primeiro numa busca de conhecer a realidade da escola, dos alunos e dos profissionais da educação que compõem a equipe da unidade escolar.

Os profissionais que atuam na escola devem ter um conceito de homem, de mundo, do significado e do sentido da ação socioeducativa para a construção de um mundo melhor, mais justo, mais humano e mais solidário.

Assim esse trabalho culminou em uma série de ações e projetos. Sua implantação na escola está se dando de forma contínua e podemos observar que estamos no caminho certo, em busca de uma educação que valorize o ser humano em um local onde os alunos perderam muito, perderam a liberdade de ir e vir. Essa privação não implica, contudo, na supressão dos seus direitos ao respeito, dignidade, privacidade, integridade física, psicológica, moral e ao desenvolvimento pessoal e social.

Concluindo, o fazer pedagógico evidenciou a necessidade de dar continuidade nos Projetos em andamento, tendo em vista que os alunos ao perceberem que conseguem apreender, que conseguem evoluir no aprendizado, que conseguem se inserir nesse mundo letrado, do qual a maioria se sentia à margem. Reveem a escola e por que não dizer, reveem suas próprias histórias. Ao possibilitar ludicidade no espaço escolar, dentro do centro socioeducativo, levamos não só conhecimento ou informação mais um pouco de alegria aos adolescentes que vivem sob o signo da tristeza e do sofrimento.

\section{Referências Bibliográficas}

BRASIL, Código de Menores. Lei n. 6697/79. 2 ed. Brasília: Senado Federal/Sub-Secretaria de Edições Técnicas, 1984.

BRASIL, Estatuto da Criança e do Adolescente. Lei 8069/90. Brasília: Congresso Nacional, 1990.

DELORS, Jacques e outros. Relatório para a UNESCO, da Comissão Internacional.

COSTA, Antonio Carlos Gomes da. Protagonismo juvenil: adolescência, educação e participação democrática. Salvador, Fundação Odebrecht, 2000.

COSTA, Antonio Carlos Gomes da. As bases éticas da ação Socioeducativa. Brasília: Secretaria Especial dos Direitos Humanos, 2006. 
DEMO, Pedro. Política social, educação e cidadania. Campinas: Papirus. 1994. Editora Adônis, 2005.

FREIRE, Paulo. A educação na cidade. São Paulo: Cortez, 1995.

FREIRE, Paulo. Pedagogia do oprimido. 17. ed. Editora. Paz e Terra. Rio de janeiro, 1987.

GOLEMAN, D. Inteligência Emocional. São Paulo: Saraiva, 1997.

MANGUEL, Alberto. Uma história da leitura. Companhia das Letras. São Paulo 1997.

SOARES, Magda. Letramento: um tema em três gêmeos. 2. Ed. Belo Horizonte: autêntica, 2000.

VYGOTSKY, L, S. A formação social da mente. São Paulo: Martins Fontes 1999. 